\title{
Uncovering the Forgotten Effect of Superior Cervical Ganglia on Pupil Diameter in Subarachnoid Hemorrhage: an Experimental Study
}

\author{
Mehmet Resid ONEN ${ }^{1}$, Ilhan YILMAZ ${ }^{2}$, Leyla RAMAZANOGLU ${ }^{3}$, Mehmet Dumlu AYDIN ${ }^{4}$, Sadullah KELES ${ }^{5}$, \\ Orhan BAYKAL ${ }^{5}$, Nazan AYDIN ${ }^{6}$, Cemal GUNDOGDU7
}

${ }^{1}$ Umraniye Teaching and Research Hospital, Neurosurgery Clinic, Istanbul, Turkey ${ }^{2}$ Sisli Teaching and Research Hospital, Neurosurgery Clinic, Istanbul, Turkey ${ }^{3}$ FSM Teaching and Research Hospital, Neurology Clinic, Istanbul, Turkey ${ }^{4}$ Ataturk University Medical Faculty, Department of Neurosurgery, Erzurum, Turkey ${ }^{5}$ Ataturk University Medical Faculty, Department of Ophthalmology, Erzurum, Turkey ${ }^{6}$ Bakirkoy Teaching and Research Hospital, Psychiatry Clinic, Istanbul, Turkey ${ }^{7}$ Ataturk University Medical Faculty, Department of Pathology, Erzurum, Turkey

\section{ABSTRACT}

AIM: To investigate the relationship between neuron density of the superior cervical sympathetic ganglia and pupil diameter in subarachnoid hemorrhage.

MATERIAL and METHODS: This study was conducted on 22 rabbits; 5 for the baseline control group, 5 for the SHAM group and 12 for the study group. Pupil diameters were measured via sunlight and ocular tomography on day 1 as the control values. Pupil diameters were re-measured after injecting $0.5 \mathrm{cc}$ saline to the SHAM group, and autologous arterial blood into the cisterna magna of the study group. After 3 weeks, the brain, superior cervical sympathetic ganglia and ciliary ganglia were extracted with peripheral tissues bilaterally and examined histopathologically. Pupil diameters were compared with neuron densities of the sympathetic ganglia and ciliary ganglia which were examined using stereological methods.

RESULTS: Baseline values were; normal pupil diameter $7.180 \pm 620 \mu \mathrm{m}$ and mean neuron density of the superior cervical sympathetic ganglia $6.321 \pm 510 / \mathrm{mm}^{3}$, degenerated neuron density of ciliary ganglia was $5 \pm 2 / \mathrm{mm}^{3}$ after histopathological examination in the control group. These values were measured as $6.850 \pm 578 \mu \mathrm{m}, 5.950 \pm 340 / \mathrm{mm}^{3}$ and $123 \pm 39 / \mathrm{mm}^{3}$ in the SHAM group and $9.910 \pm 840$ $\mu \mathrm{m}, 7.950 \pm 764 / \mathrm{mm}^{3}$ and $650 \pm 98 / \mathrm{mm}^{3}$ in the study group. A linear relationship was determined between neuron density of the superior cervical sympathetic ganglia and pupil diameters $(p<0.005)$. Degenerated ciliary ganglia neuron density had an inverse effect on pupil diameters in all groups $(p<0.0001)$.

CONCLUSION: Highly degenerated neuron density of the ciliary ganglion is not responsible for pupil dilatation owing to parasympathetic pupilloconstrictor palsy, but high neuron density of the pupillodilatatory superior cervical sympathetic ganglia should be considered an important factor for pupil dilatation.

KEYWORDS: Subarachnoid hemorrhage, Pupil diameter, Superior cervical ganglia, Sympathetic innervation, Light reflex 


\section{INTRODUCTION}

$\mathrm{T}$ The parasympathetic innervation of the pupillary light reflex is supplied by postganglionic fibers of the ciliary ganglion of the third cranial nerve (oculomotor nerve). The fibers originate from the Edinger-Westphal nucleus $(E W N)$ in the mesencephalon and they are responsible for constriction of the pupils (29). The dilation of pupils is regulated by the sympathetic postganglionic fibers of the superior cervical ganglia (SCGs) which are located along the cervical and thoracic parts of spinal cord (34). Subarachnoid hemorrhage $(\mathrm{SAH})$ causes neuronal degeneration in the ciliary ganglia (CG) due to oculomotor nerve (OMN) ischemia. This seems to be responsible for the abnormalities of light reflex in SAH (2). Horner's syndrome, which consists of miosis, ptosis and ipsilateral facial anhidrosis, is seen when there is an interruption of the sympathetic nerve supply to the neck and head (22). Pathological causes include lesions in the brainstem or cervical part of the spinal cord (32).

$\mathrm{SAH}$ is a serious and fatal disorder. It causes extracranial complications besides intracranial complications $(1,11,25,52)$. One of the most common physical signs seen in SAH patients is the abnormalities of pupil diameters. Once the blood leaks into the subarachnoid space, it causes microembolisms and vasospasm of the vascular feeding structures surrounding the roots of oculomotor nerve. These vascular changes damage both the oculomotor nerve and the ciliary ganglia $(14,38)$. Oculomotor nerve involvement may also be seen during the days after SAH. Delayed cerebral ischemia causes cerebral edema and this swelling is responsible for the involvement. Changes in pre-ganglionic parasympathetic fibers of oculomotor nerve result in mydriasis in the late phase of $\mathrm{SAH}$ (38). Oculomotor nerve palsy seems to be the most common cause of pupillary irregularities, but we believe that the role of the sympathetic system should be also considered as another important factor.

Spinal cord disorders, such as ischemic myelopathy (15), hemi-spinal cord infarction (30), cervical intramedullary ependymoma (21), and cervical epidural hematoma (46), also cause Horner's syndrome. The role of sympathetic systems regulating pupil diameter should be also investigated if any light reflex anomalies are observed during $\mathrm{SAH}$. In the current study it was noticed that superior cevical ganglia neuron density has an interesting role on the regulation of pupil diameter as well as on the oculomotor nerve network following SAH. Superior cervical sympathetic ganglia with high neuron density may cause pseudodilatation of the pupils or oculomotor network palsy-induced mydriasis may be augmented by explained mechanisms. Radicular oculomotor nerve ischemia and related ciliary ganglion degeneration were also observed to have important roles in mydriatic pupil development. High neuron density of superior cervical sympathetic ganglia should be considered an important factor in the development of mydriatic pupil in both normal conditions and in various neurological pathologies that affect the light reflex. To the best of our knowledge, this condition has not been studied in the literature yet.
The aim of this study was to investigate the role of the sympathetic system on pupil diameter regulation, because studies on how the pupil diameter is regulated by the autonomic nervous system are inadequate. All physicians know that the light reflex is controlled by parasympathetic fibers of the oculomotor nerves and sympathetic fibers of the SCG. However, no physician has noticed the sympathetic system's role in determining the pupil diameter in both diagnostic and therapeutic practice.

\section{MATERIAL and METHODS}

This study was conducted on 22 rabbits $(2.5-3 \mathrm{~kg})(3 \pm 0.5 \mathrm{~kg})$ with 5 used as the baseline control group, 5 as the SHAM group and 12 as the study group. The pupil diameters of all animals were measured via sunlight and ocular tomography on the first day and those results were accepted as control values. All animals were followed up for three weeks with daily pupil diameter measurements. The SHAM and study groups were anesthetised with subcutaneous $15 \mathrm{mg} / \mathrm{kg}$ of lidocaine hydrochloride, $25 \mathrm{mg} / \mathrm{kg}$ of ketamine hydrochloride and $1 \mathrm{mg} / \mathrm{kg}$ of acepromazine. Then, posterior craniocervical region was shaved and $0.5 \mathrm{cc}$ autologous blood -taken from the auricular artery- injected into the cisterna magna of the animals belonging to study group. Only $0.5 \mathrm{cc}$ physiological saline was injected into the cisterna magna of the rabbits in the SHAM group. Three rabbits were excluded from the study because they died due to technical problems. The remaining animals were followed-up for three weeks and then sacrificed under general anesthesia. SCGs and ciliary ganglions were examined histopathologically using Stereological methods. For the stereological analysis, the specimens were dehydrated in $10 \%$ formalin solution and embedded in paraffin blocks and $5 \mu \mathrm{m}$ sections were stained with hematoxylin \& eosin and Terminal deoxynucleotidyl transferase dUTP nick end labeling (TUNEL) methods (Figures 1, 2) $(9,19)$.

The physical dissector method was used to estimate the numbers of normal and degenerated neurons in both ciliary and SCGs $(9,19,48)$. Data were obtained from dissector pairs, which consisted of parallel sections taken at specified intervals until the tissue samples were exhausted. Two consecutive reference and look-up sections were prepared on each slide. All of the 20 dissector pairs were taken from each specimens to analyse the neuron densities of CG and SCG. Unbiased counting frames were placed on consecutive sections on a computer screen to estimate the neuron numbers in the ganglions according to the dissector method (Figure 3A,B). The bottom and the left hand edges of the frames were considered as exclusion lines with the extension lines. Other boundaries of the frames and the top-right corner were accepted as inclusion points and particles on these lines or located inside of frames counted as a dissector partide. The visible neurons in the reference section of the ganglions were counted as countable rational neurons. In order not to double the number of dissector pairs without taking new sections, reference and look-up sections were turned backward $(9,17,19,48)$.

The mean numerical density of CG and SCG neurons (NvGN) per $\mathrm{mm}^{3}$ was calculated using the following formula: 
$N v G N=\sum Q^{-} N / t x A$

The total counted numbers of neurons appearing only in the reference sections are shown as $\left\{\right.$ QUOTE $\left.\sum Q^{-} N\right\}$; section thickness is presented as $t$ and area of the counting frame is shown as $A$. The Cavalieri volume estimation method was used to estimate the total number of neurons in each ganglion. The total neuron numbers were estimated by multiplication of the volume $\left(\mathrm{mm}^{3}\right)$ and numerical density of neurons in each ganglion $(9,19)$.

\section{Statistical Analysis}

Counted neuron numbers were presented as mean \pm SD. The data were analyzed with the non-parametric Mann-Whitney U-test.

\section{RESULTS}

The normal pupil diameter was measured as $7.180 \pm 620$ $\mu \mathrm{m}$ in all animals before the experiment. These values were determined as $6.850 \pm 578 \mu \mathrm{m}$ in the SHAM group and $9.210 \pm 840 \mu \mathrm{m}$ in the study group.
$\mathrm{SAH}$-induced brain edema, clot formation, displacements and bloody material leakage into the oculomotor nerve roots and basal brain arteries, microembolism in the basilar artery and arachnoid pia adhesions were detected on the macroscopical examinations of the brains in the study group. Basal cisterns and subarachnoid space of the OMNs were not examined well due to meningeal and cortical inflammatory changes (Figure 1). On microscopic examination of the ciliary ganglia, the surface and the nucleus of degenerated neurons were irregular with prominent indentations. Cellular angulations, cytoplasmic condensation, nuclear shrinking, nucleus migration to the periphery and peri-cytoplasmic halo formation were regarded as degeneration criteria of neurons $(9,19)$. Apoptotic neuronal degeneration was detected by TUNEL method in CG (34\%), but apoptotic degeneration was not significant in SCG because SCG is supplied by the external carotid artery that was rarely affected by SAH-related vasospasm (4\%).

The stereological analysis of SCG and CG was as follows: mean neuron density of superior cervical sympathetic ganglia was $6.321 \pm 510 / \mathrm{mm}^{3}$ and degenerated neuron density of ciliary ganglia was $5 \pm 2 / \mathrm{mm}^{3}$ after histopathological examination in

Table I: The Stereological Analysis of SCG and Ciliary Ganglia is Presented for the 3 Groups. There was a Linear Relationship Between the Neuron Density of the Superior Cervical Sympathetic Ganglia and Pupil Diameters $(p<0.005)$, but Degenerated Ciliary Ganglia Neuron Density had an Inverse Effect on Pupil Diameters in all Groups $(p<0.0001)$

\begin{tabular}{lccr}
\hline & Pupil Diameter $(\boldsymbol{\mu m})$ & Normal Neuron in SCG/mm & Degenerated Neuron in CG/mm $^{3}$ \\
\hline Normal group & $7.180 \pm 620$ & $6.321 \pm 510$ & $5 \pm 2$ \\
\hline SHAM group & $6.850 \pm 578$ & $5.950 \pm 340$ & $123 \pm 39$ \\
\hline Study group & $9.910 \pm 840$ & $7.950 \pm 764$ & $650 \pm 98$ \\
\hline
\end{tabular}

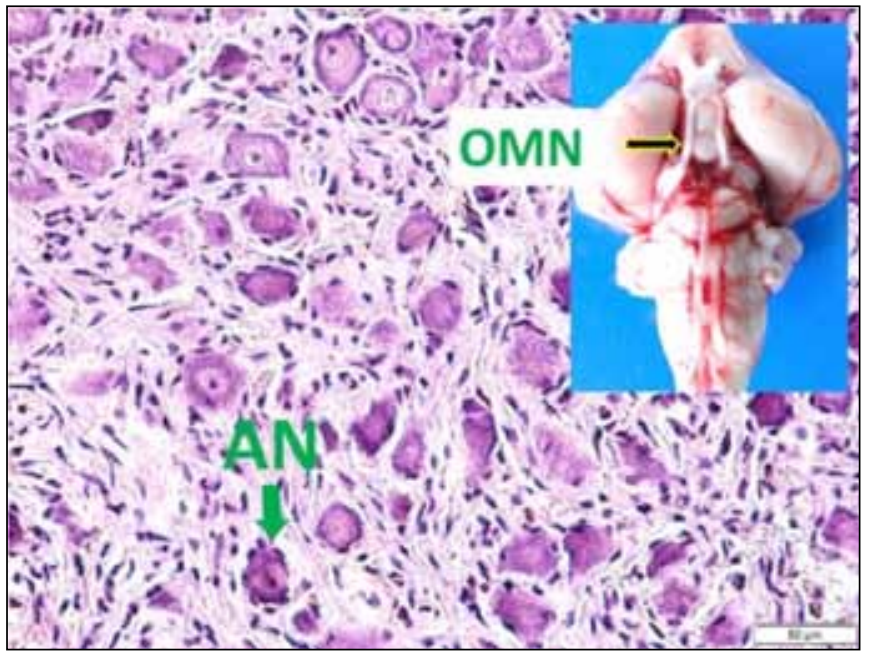

Figure 1: A photographic image of oculomotor nerves (OMN) and related anatomical structures of a rabbit in the right upper corner. At the base, the histological appearance of ciliary ganglion with degenerated apoptotic neurons (AN) is seen (TUNEL, $x 4$ ).

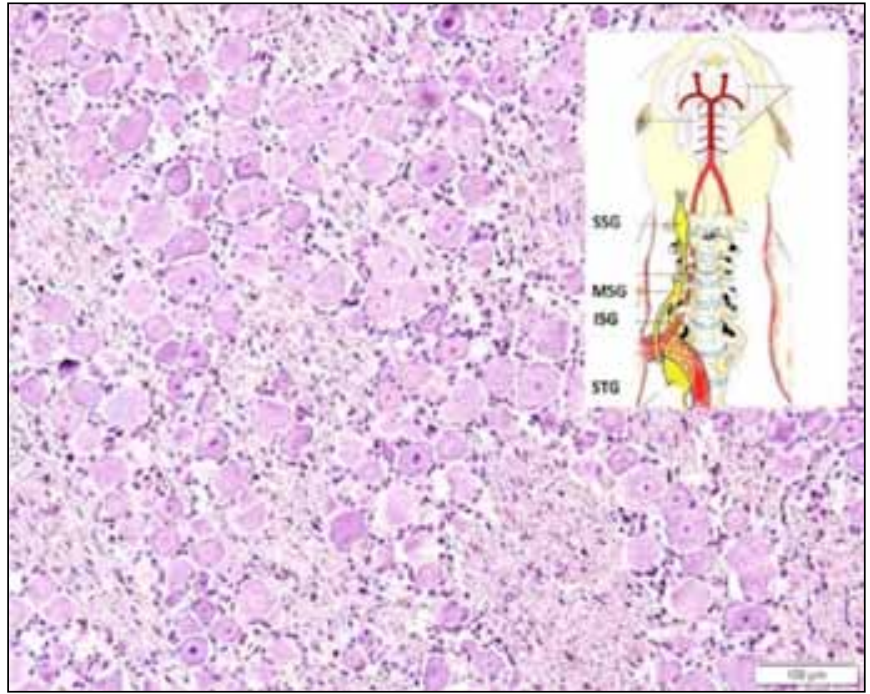

Figure 2: A schematic drawing of cervical ganglia and related anatomical structures of a rabbit in the right upper corner (SSG: Superior cervical sympathetic ganglion, MSG: Middle cervical sympathetic ganglion, ISG: Inferior cervical sympathetic ganglion, STG: Stellate ganglion). At the base, histological appearance of superior cervical sympathetic ganglion is seen (TUNEL, $x 4)$ (The schmatic picture was drawned by S. Kayaci). 
the control group. These values were determined as $6.850 \pm 578$ $\mu \mathrm{m}, 5.950 \pm 340 / \mathrm{mm}^{3}$ and $123 \pm 39 / \mathrm{mm}^{3}$ in the SHAM group and $9.910 \pm 840 \mu \mathrm{m}, 7.950 \pm 764 / \mathrm{mm}^{3}$ and $650 \pm 98 / \mathrm{mm}^{3}$ in the study group. There was a linear relationship between the neuron density of superior cervical sympathetic ganglia and pupil diameters $(p<0.005)$, but degenerated ciliary ganglia neuron density was determined to have an inverse effect on pupil diameters in all groups $(p<0.0001)$. Radicular oculomotor nerve ischemia and related ciliary ganglion degeneration were seen to have important roles in mydriatic pupil development. High neuron density of superior cervical sympathetic ganglia should also be considered as an important factor in the development of mydriatic pupil in both normal conditions and in various neurological pathologies that affect the light reflex (Figures 4-6).

\section{DISCUSSION}

The pupillary light reflex is considered a multineuron arc pathway. The impulses from the retinal ganglion cells travel through the optic nerve, optic chiasm and optic tract and ascend to the olivary pretectal nucleus that lies close to the superior colliculus. Then the impulses pass to the parasympathetic nuclei (Edinger-Westphal nuclei) of the oculomotor nerve and travel to the ciliary ganglion. These fibers are responsible for controlling the muscles of the iris via the short ciliary nerves. The accessory oculomotor nuclei and the periaqueductal gray receive input from the olivary pretectal nucleus and act upon the pupillary light reflex. Fibers from the interstitial nucleus of Cajal, nucleus of the posterior commissure and nucleus of Darkschewitsch coming to the Edinger-Westphal nucleus are small dense projections. On the other hand, the rostral part of the periaqueductal gray sends high-density projections to the Edinger-Westphal nucleus. The nucleus of Darkschewitsch and periaqueductal gray also send fibers to the thoracic level of the spinal cord. Current studies have shown that the regulation of the parasympathetic preganglionic neurons in the Edinger-Westphal nucleus is supplied by dual pathways: the pretectal olivary nucleus -Edinger-Westphal pathway and the pathway between accessory oculomotor nuclei and periaqueductal gray. Light sensitive impulses travel from olivary pretectal nucleus- periaqueductal gray- spinal cord and reach the sympathetic superior cervical ganglion that also controls iris musculature. Periaqueductal gray is considered to have a function both in the parasympathetic and sympathetic regulation of the pupillary light reflex (29).

The autonomic nervous system has various effects on ocular functions. It manages these functions via the pathway of parasympathetic innervation originating from ciliary and pterygopalatine ganglia and also through sympathetic innervation through postganglionic fibers originated from the superior cervical ganglion. The ciliary ganglion sends fibers to the ciliary body and the sphincter pupillae muscle of the iris. They are responsible for accommodation and constriction of the pupils. The superior cervical ganglion sends fibers to the dilator pupillae for pupil dilation. These structures are supplied by projections from the pterygopalatine and superior cervical ganglion. Additionally the trigeminal sensory fibers influence many of the regions of the eye and also have some effect on neurons within the ciliary and pterygopalatine ganglia (34).

Any interruption in the pathway from the nucleus to the orbit can result the oculomotor nerve. Lesions at the level
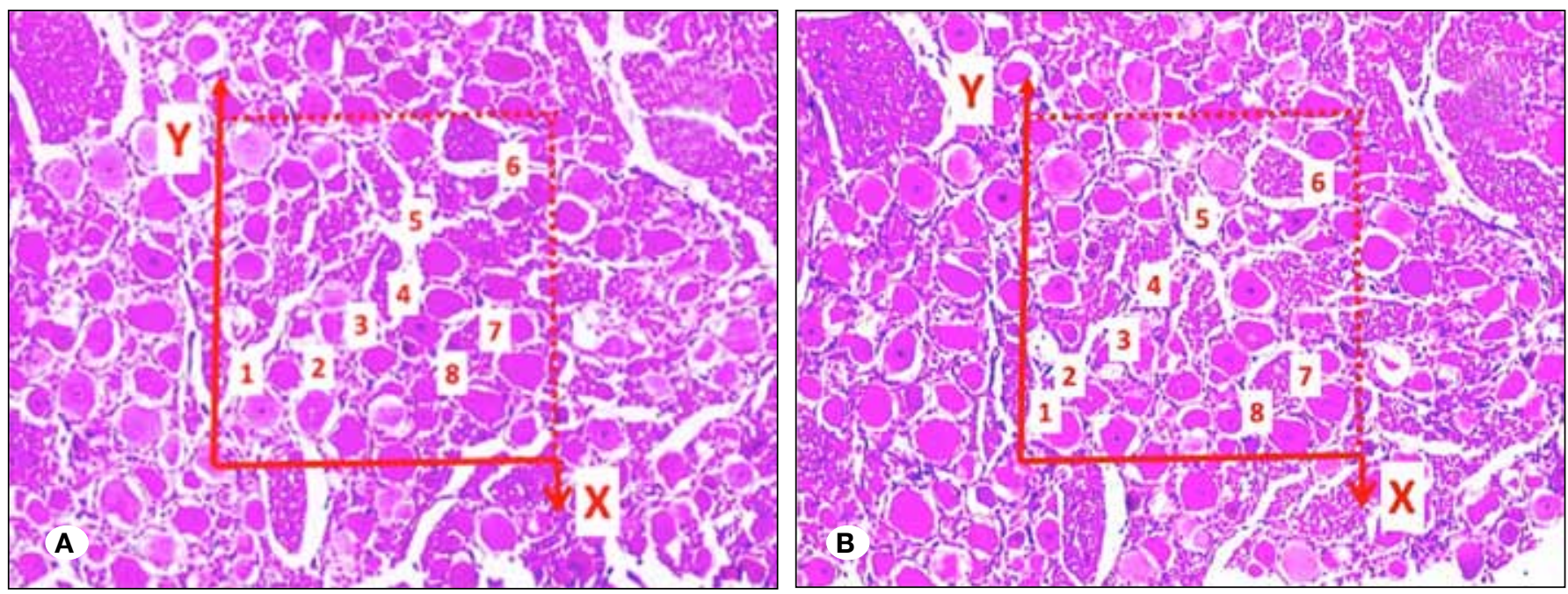

Figure 3 A,B: Stereologic cell counting of the superior cervical ganglia in a rabbit. Purpose of the physical dissector method wherein micrographs in the same fields of view $(\mathbf{a}, \mathbf{b})$ were cut off in two parallel, adjacent thin sections separated by a distance of $5 \mu \mathrm{m}$. The upper and right lines in the unbiased counting frames characterize the inclusion lines, and the lower and left lines, containing the extensions, are exclusion lines. The neuronal nucleoli touching the inclusion lines were excepted, and the nucleoli profiles touching the inclusion lines and positioned inside the frame were counted as dissector units unless their profile protracted up to the reference section. The number of neurons from the two dissectors appears in a volume given by the creation of the counting frame area and the distance between the sections. The numerical density of the neurons is estimated as NvGN=SQ-GN/txA. In this claim, the nucleoli marked with ' $1,4,5.6$ ' are dissector particles in A. Section B shows them as they disappeared. The nucleoli marked with ' $2,3,7,8$ ' are not a dissector particle in A. Section B shows '3,4,6-8' as it disappeared (H\&E, x40). 
of the mesencephalic nucleus, interpedincular fossa, sinus cavernosus, and orbit cause third cranial nerve dysfunctions. Ischemic or hemorrhagic lesions or mass lesions cause the paralysis of oculomotor nerve lead to oculomotor nerve palsy (27). Trauma and bacterial meningitis are other reasons for isolated oculomotor nerve palsy $(23,41)$. Involvement of the oculomotor nerve is also frequently seen in pachymeningitis (38). Increased intracranial pressure, meningitis and $\mathrm{SAH}$ are predisposing factors in nerve palsy (26). Pupillary autonomic mechanisms have been regained and re-normalized in the presence of aberrant autonomic regeneration in the ciliary ganglion (36). Without herniation, we can see a dilated, unreactive pupil to light in meningitis due to the degeneration of light reflex modulation pathways (35).

Although the ciliary ganglion is a parasympathetic ganglion, some sensitive and sympathetic fibers are found in ball. Parasympathetic pupillodilatatory fibers originating from the oculomotor nerve travel as preganglionic fibers, synapse in the Edinger-Westphal nucleus and continue as postganglionic fibers innervating sphincter pupillae and ciliary muscles through the short ciliary nerves. The sensitive root from the nasociliary nerve and the sympathetic root from the internal carotid artery do not synapse. Some mammals do not have

\section{OCULUS - PENTACAM}

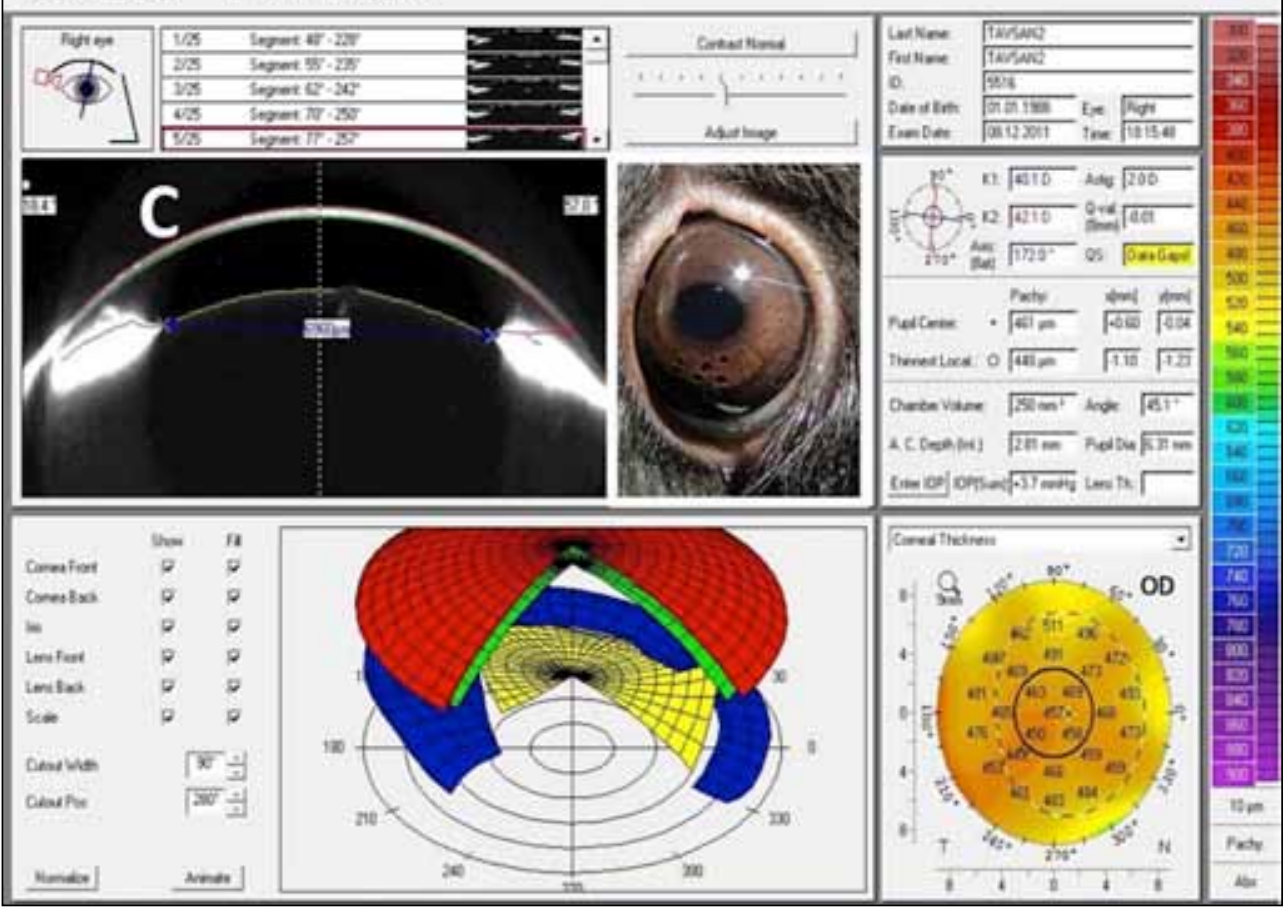

Figure 4: Image of normal rabbit pupil diameter and ocular tomography device software document.

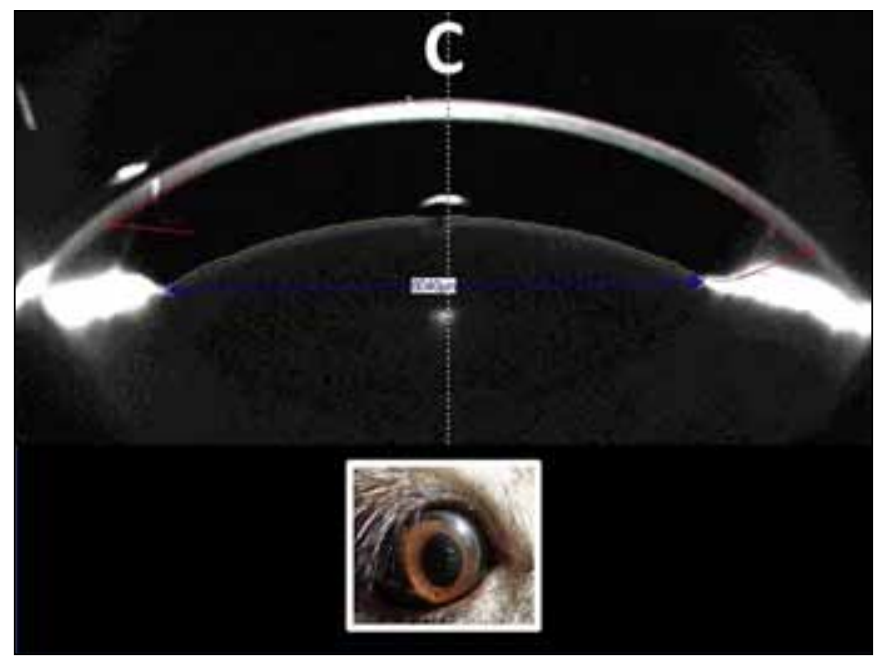

Figure 5: A less dilated pupil with low neuron density including CSG and low degenerated neuron density including CG.

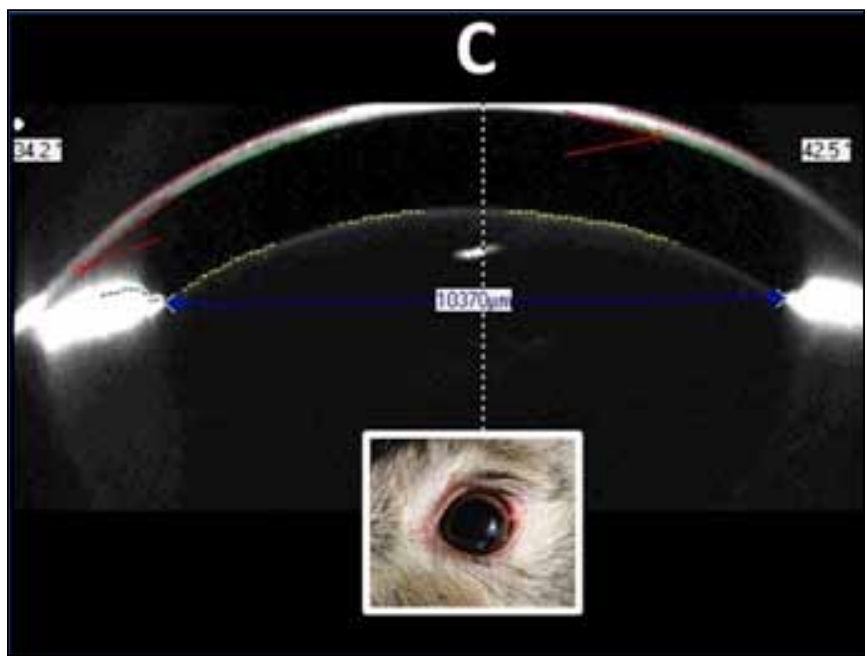

Figure 6: A more dilated pupil with high neuron density including CSG and high degenerated neuron density including CG. 
sympathetic and sensitive fibers. In the ciliary ganglion, only the parasympathetic fibers synapse. Parasympathetic postganglionic fibers innervate the constrictor muscles of the pupils and ciliary muscles of the lens. This autonomous pathway regulates accommodation and light reflexes $(42,47,53)$ because the cisternal parts of the oculomotor nerve and optic nerve are covered by meninges (42), and they have a rich blood supply around the nerves, and meningitis or SAH can easily influence these nerves. Thus, SAH or meningitis can easily damage the vessels of these nerves in the subarachnoidal spaces. As a result, neuropraxia, axonolysis and intraneuronal fibrosis, oculomotor nerve palsy and visual anomalies can be seen due to microembolism of the feeding arteries $(13,14,43)$.

Ciliary ganglia contain multipolar and larger neurons compared to typical autonomic ganglia. Although, one week following the preganglionic damage, neurons change their shape and become irregular with nuclear displacement to the periphery of the neuron; at 21 and 28 days following surgery, neurons again become normal and CG functions start to re-normalize. Following the $4^{\text {th }}$ day of surgery, nearly all axon terminals are affected and 45 days after surgery axon terminals cannot be seen. The satellite cells, macrophages and Schwann cells remove the debris of degenerated ganglial materials $(55,56)$. Complete cell damage occurs in all of the ganglial neurons after SAH, because of total interruption of preganglionic innervation $(38,54,56)$. Aneurysmatic compression lesions of the oculomotor nerve also lead to cellular necrosis and loss in the ciliary ganglia (38).

In this study, we aimed to understand the relationship between the sympathetic system and the caliber of the pupils in $\mathrm{SAH}$, because previous studies are inadequate. We all know that parasympathetic fibers of the oculomotor nerve are responsible for the light reflex. However, few of us know that sympathetic fibers of the superior cervical ganglion have a major affect on controlling the pupil diameter in both therapeutic and diagnostic practice. Particularly, spinal cord and its parts have not been studied in spinal SAH.

The light reflex is very important in clinical practice, particularly for neurological disorders. Not only is the oculomotor nerve function checked, but sympathetic system examination should also conducted during the clinical approach, especially in SAH. We should keep in mind that the spinal sympathetic center (Th-1)-originated pupilloregulatory network disorders lead to pinpoint or anisocoric pupils and serious diagnostic problems may be inevitable.

\section{Stereological Method}

Estimation of the normal and degenerated neurons in each are important, because a bias can be seen with previous counting methods. In this study, stereological methods were preferred to examination of the ganglia. Stereology is more useful, because it is a mathematical method associated with three-dimensional morphometric analysis arising from the structural and multidimensional derangements. It also defines quantitative measurements of shape, size, number and orientation in space $(6,17,48)$. Cavalieri and others described dissector method in their former studies $(9,18,19,40)$. Stereology can easily estimate the neuron numbers, intuitively simple, free from assumptions about particle shape, size, and orientation because this method is not affected by over-protection and truncation.

Transient pupillary dilatation occurs in migraine, because of the interruption of parasympathetic supply (40). In childhood, fixed, dilated pupils are also seen due to interruption of parasympathetic innervation (20). Parasympathetic fibers of OMN of the eyes are more affected in connective tissue disorders, because of ischemia in the ciliary ganglion $(3,10)$. Axial length of the eye and choroidal thickness are controlled by the parasympathetic nervous system (44). There is a correlation between the rate of diabetic retinopathy and autonomic neuropathy (45). Pupil reflexes have been reported to be abnormal in $88.5 \%$ of diabetics with proliferative retinopathy $(7,45)$. According to current research, because of the involvement of the feeding arteries of oculomotor nerve, axonal degeneration develops so that neuronal damage was seen in the ciliary ganglia. Aneurysmatic compression is also known to damage neurons in the ciliary ganglion (38).

Autonomic neuropathy is also correlated with primary glaucomas. There is parasympathetic dysregulation in ocular hypertensive patients (7). Microscopic examination of ciliary ganglia of glaucomatous patients has shown a degredation of the cytoplasm, proliferation of cells, and mitochondrial and nuclear degeneration $(7,12)$. Age-related changes can also be seen in the CG of healthy subjects. Age-related changes such as degeneration, hemorrhage, and proliferation around the nucleus, it is possible to say that ciliary ganglia are responsible for neuropathic innervation of eye membranes and take part in the glaucomatous process (50). Meningitis can induce inflammatory changes, vasculitis, microembolism and vasospasm of the brain arteries and the ophthalmic artery so that cellular injury and necrosis can be triggered in both oculomotor nerves and the ciliary ganglion $(13,14,43)$. These histopathological degenerations of the ciliary ganglia may be responsible for pupillary diameter abnormalities.

\section{Pupil Diameter Regulating Servical Sympathetic Ganglia}

Preganglionic neurons are situated in spinal segments from $\mathrm{T} 1$ to T10. These sympathetic preganglionic neurons send fibers to the satellite ganglion. Neurons associated with the superior cervical ganglion are situated in segments T1 to T8. The soma of these neurons travel in the rostrocaudal direction and dendrites continue to the intermediolateral cell column. It has been reported that only $5 \%$ of neuron axons innervated by the superior cervical ganglion do not pass through the stellate ganglion and almost $95 \%$ of the neurons innervating the superior cervical ganglion have axons that pass through the stellate ganglion (39).

\section{Sympathetic Pathologies}

Horner syndrome consists of ptosis, miosis and ipsilateral facial anhidrosis. The lesions that cause compression at the level of C4-C5 cause interruption of the oculo-sympathetic pathway, so Horner syndrome occurs (32). The diameter of the pupil is smaller (5). Horner syndrome involves an injury affecting the ocular sympathetic nerve that gives rise to miosis, palpebral 
ptosis and enophthalmos, and is accompanied by hemifacial anhidrosis in its complete forms. Lesions around endothoracic fascia cause Horner syndrome, because this area is closely related to the cervical sympathetic chain. Fibrosis is seen in these cases. After thoracic surgery, Horner syndrome can be seen in the acute phase or as a later complication (24).

Horner syndrome can be triggered after viral infections in the cervical spinal cord (31). Congenital or post-traumatic cervicothoracic metabolic disorders (22), cervical epidural hematoma (46), brachial plexus lesions (16), spinal invasion of the left apical lung cancer (51), a cervical intramedullary ependymoma (21), ischemic myelopathy (15), spinal cord ischemia after endovascular repair of the descending thoracic aorta (4), hemi-spinal cord infarction secondary to vertebral artery dissection in congenital afibrinogenemia (30), ventromedial infarction of the brain stem (49) and Chiari malformations with a syrinx extending to the $\mathrm{C} 2$ to $\mathrm{C} 4$ level (28) may be responsible for Horner syndrome. Healing can be seen in some patients after traumatic or penetrating cervical spinal cord injuries (33).

\section{CONCLUSION}

Neuronal degeneration of the ciliary ganglia induced by $\mathrm{SAH}$ may be responsible for mydriatic pupil. It is considered that the pre-synaptic parasympathetic degeneration of the ciliary ganglia could cause ciliary ganglia degeneration, same as the anterograde transneuronal degeneration process in $\mathrm{SAH}$. In this study, since both optic nerve and oculomotor nerve pathways of light reflex network were affected by $\mathrm{SAH}$, degeneration of the ciliary ganglia may be responsible for the light reflex abnormalities following $\mathrm{SAH}$. Inflammation of the oculomotor nerve in the subarachnoidal space can result in pre-ganglionic axotomy for ciliary ganglia. Abnormalities of light and accommodation reflexes and tonic pupil development are not only secondary to oculomotor nerve involvement, but also secondary to neuronal degeneration in ciliary ganglia $(8,27)$.

Radicular oculomotor nerve ischemia and related ciliary ganglion degeneration have important roles in the development of mydriatic pupil. However, it should be considered that high neuron density of superior cervical sympathetic ganglia may also be an important factor in the development of mydriatic pupil in both normal conditions and in various neurological pathologies that affect the light reflex. To the best of our knowledge, this has not been previously investigated in the literature.

\section{REFERENCES}

1. Araz O, Aydin MD, Gundogdu B, Altas E, Cakir M, Calikoglu C, Atalay C, Gundogdu C: Preventive role of hilar parasympathetic ganglia on pulmonary artery vasospasm in subarachnoid hemorrhage: An experimental study. Turk Neurosurg 25: 519525, 2015

2. Aydin MD, Onder S, Ulvi H, Onder A, Baykal O: Histopathological alterations in ciliary ganglions in meningitis: An experimental study. Minim Invasive Neurosurg 48:297-301, 2005
3. Bertinotti L, Pietrini U, Rosso AD, Casale R, Colangelo N, Zoppi M, Matucci-Cerinic M: The use of pupillometry in joint and connective tissue diseases. Ann NY Acad Sci 966:446455, 2002

4. Böckler D, Kotelis D, Kohlhof $P$, von Tengg-Kobligk $H$, Mansmann U, Zink W, Hörner C, Ortlepp I, Habel A, Kauczor HU, Graf B, Allenberg JR: Spinal cord ischemia after endovascular repair of the descending thoracic aorta in a sheep model. Eur J Vasc Endovasc Surg 34:461-469, 2007

5. Cagan E, Sayin R, Dogan M, Peker E, Cagan HH, Caksen $\mathrm{H}$ : Bilateral brachial plexus palsy and right Horner syndrome due to congenital cervicothoracal syringomyelia. Brain Dev 32:595-597, 2010

6. Chang Z, Shen Z, Sun Y, Wang N, Cao D: Early repair treatment of electrical burns and recovery of tendons and nerves. Report of 194 operations. Ann NY Acad Sci 888:327-333, 1999

7. Clark CV, Mapstone R: Anterior segment autonomic dysfunction in ocular hypertension. Doc Ophthalmol 64:201 $-207,1986$

8. Clark CV, Mapstone R: Parasympathetic denervation hypersensitivity of the iris in ocular autonomic nerve function in proliferative diabetic retinopathy. Eye 2:96-101, 1988

9. Cruz-Orive LM, Weibel ER: Recent stereological methods for cell biology: A brief survey. Am J Physiol 258:148 -156, 1990

10. Currie J, Lessell S: Tonic pupil with giant cell arteritis. $\mathrm{Br} \mathrm{J}$ Ophthalmol 68: 135-138, 1984

11. Eseoglu M, Yilmaz I, Karalar M, Aydin MD, Kayaci S, Gundogdu $\mathrm{C}$, Onen MR: The role of sympathectomy on the regulation of basilar artery volume changes in stenoocclusive carotid artery modeling after bilateral common carotid artery ligation: An animal model. Acta Neurochir 156: 963-969, 2014

12. Faschinger $\mathrm{C}$, Kleinert $\mathrm{K}$ : Histologic and ultrastructural findings in the ciliary ganglion in normal eyes and in patients with glaucoma. Klin Monatsbl Augenheilkd 189:400-401, 1986 (In German)

13. Ferreira RC, Phan G, Bateman JB: Favorable visual outcome in cryptococcal meningitis. Am J Ophthalmol 124: 558-560, 1997.

14. Giombini S, Ferraresi S, Pluchino P: Reversal of oculomotor disorders after intracranial aneurysm surgery. Acta Neurochir 112:19-24, 1991

15. Greene CE, Higgins RJ: Fibrocartilaginous emboli as the cause of ischemic myelopathy in a dog. Cornell Vet 66:131142, 1976

16. Grundy DJ, Silver JR: Problems in the management of combined brachial plexus and spinal cord injuries. Int Rehabil Med 3: 57-70, 1981

17. Gundersen $\mathrm{HJ}$ : Notes on the estimation of the numerical density of arbitrary particles: The edge effect. J Microsc 111: 219-223, 1977

18. Gundersen HJ: Stereology of arbitrary particles. A review of unbiased number and size estimators and the presentation of some new ones, in memory of William R. Thompson. J Microsc 143: 43-45, 1986

19. Gundersen HJ, Bendtsen TF, Korbo L, Marcussen N, Moller A, Nielsen K, Nyengaard JR, Pakkenberg B, Sorensen FB, Vesterby A: Some new, simple and efficient stereological methods and their use in pathological research and diagnosis. APMIS 96: 379-394, 1988 
20. Hersh JH, Douglas C, Houston J, Weisskopf B: Familial iridology. J Pediatr Ophthalmol Strabismus 24:49-50, 1987

21. Hopf HC: Intermittent Horner's syndrome on alternate sides: A hint for locating spinal lesions. J Neurol 224:155-157, 1980

22. Horner PJ, Stokes BT: Fetal transplantation following spinal contusion injury results in chronic alterations in CNS glucose metabolism. Exp Neurol 133:231-243, 1995

23. Ing EB, Sullivan TJ, Clarke MP, Buncic JR: Oculomotor nerve palsies in children. J Pediatr Ophthalmol Strabismus 29:331336, 1992

24. Jimenez Caballero PE, Garcia Montero MR: Deferred Horner syndrome following thoracoplasty. Rev Neurol 36:935-937, 2003

25. Kayaci S, Kanat A, Aydin MD, Musluman AM, Eseoglu M, Karalar M, Gundogdu C: Role of neuron density of the stellate ganglion on regulation of the basilar artery volume in subarachnoid hemorrhage: An experimental study. Auton Neurosci 165:163-167, 2011

26. Keane JR: Intermittent third nerve palsy with cryptococcal meningitis. J Clin Neuroophthalmol 13:124-126, 1993

27. Kerr FWL, Hollowel OW: Location of pupillomotor and accommodation fibers in the oculomotor nerve. Experimental observations on paralytic mydriasis. I Neurol Neurosurg Psychiatr 27:473-481, 1964

28. Kerrison JB, Biousse V, Newman NJ: Isolated Horner's syndrome and syringomyelia. J Neurol Neurosurg Psychiatry 69:131-132, 2000

29. Klooster J, Vrensen GF: New indirect pathways subserving the pupillary light reflex: Projections of the accessory oculomotor nuclei and the periaqueductal gray to the Edinger-Westphal nucleus and the thoracic spinal cord in rats. Anat Embryol (Berl) 198:123-132, 1998

30. Laufs H, Weidauer S, Helle C, Lorenz M. Neumann-Haefelin T: Hemi-spinal cord infarction due to vertebral artery dissection in congenital afibrinogenemia. Neurology 63:1522-1523, 2004

31. Lim CC, Lee WL, Leo YS, Lee KE, Chan KP, Ling AE, Oh $H$, Auchus AP, Paton NI, Hui F, Tambyah PA: Late clinical and magnetic resonance imaging follow up of Nipah virus infection. J Neurol Neurosurg Psychiatry 74:131-133, 2003

32. Ma H, Kim I: Horner Syndrome associated with a herniated cervical disc: A case report. Korean J Spine 9:108-110, 2012

33. McCarron MO, Flynn PA, Pang KA, Hawkins SA: Traumatic Brown-Séquard-plus syndrome. Arch Neurol 58:1470-1472, 2001

34. McDougal DH, Gamlin PD: Autonomic control of the eye. Compr Physiol 5:439-473, 2015

35. McGravey AR: A dilated unreactive pupil in acute bacterial meningitis: Oculomotor nerve inflammation versus herniation. Pediatr Emerg Care 5:187-188, 1989

36. Menon V, Arya AV, Prakash P: Pupillary automatism. Indian J Ophthalmol 37: 30-31, 1989

37. Murakami K: A case of late onset group B Streptococcus meningitis with transient oculomotor nerve palsy. No To Hattatsu 31: 549-552, 1999 (In Japanese)

38. Ozkan U, Aydin MD, Gundogdu C, Onder A: Histopathologic changes in oculomotor nerve ciliary ganglion in aneurysmatic compression injuries of oculomotor nerve. Minim Invas Neurosurg 47:107-110, 2004
39. Pilowsky P, Llewellyn-Smith IJ, Minson J, Chalmers J: Sympathetic preganglionic neurons in rabbit spinal cord that project to the stellate or the superior cervical ganglion. Brain Res 577:181-188, 1992

40. Purvin VA: Adie's tonic pupil secondary to migraine. J Neuroophthalmol 15:43-44, 1995

41. Ramirez-Moreno JM, Aguirre-Sanchez JJ, Duran-Herrera C, Parrilla-Ramirez JL, Vialas-Simon J, Gonzalez-Dorrego F: Paralysis of the nucleus of the third cranial nerve secondary to a mesencephalic hematoma. Rev Neurol 29: 808-810, 1999

42. Rhoton AL: The orbit. Neurosurgery 51: 303-334, 2002

43. Sakaki T, Kinugawa K, Tanigake T, Miyamoto S, Kyoi K, Utsumi S: Embolism from intracranial aneurysm. J Neurosurg 53: 300-304, 1980

44. Schmid GF, Papastergiou GI, Lin T, Riva CE, Laties AM, Stone RA: Autonomic denervations influence ocular dimensions and intraocular pressure in chicks. Exp Eye Res 68: 573-581, 1999

45. Sharma S, Hoskin-Mott A, Benstead T, Maxner C: Correlation of the pilo-pupil ratio average, a new test for autonomic denervation, to the severity of diabetic retinopathy. Can $\mathrm{J}$ Ophthalmol 32: 170-171, 1997

46. Shen CC, Wang YC, Yang DY, Wang FH, Shen BB: BrownSéquard syndrome associated with Horner's syndrome in cervical epidural hematoma. Spine 20:244-247, 1995

47. Sinnreich Z, Nathan $\mathrm{H}$ : The ciliary ganglion in man. Anat Anz 150:287-290, 1981

48. Sterio DC: The unbiased estimation of number and sizes of arbitrary particles using the dissector. J Microsc 134: 127136, 1984

49. Terao S, Miura N, Takeda A, Takahashi A, Mitsuma T, Sobue G: Course and distribution of facial corticobulbar tract fibres in the lower brain stem. J Neurol Neurosurg Psychiatry 69:262265,2000

50. Tschernjawsky GJ, Pletschkowa EK: Morphological changes in ciliary ganglions of healthy subjects and glaucoma patients. Albrecht Von Graefes Arch Klin Exp Ophthalmol 211: 235 241, 1979 (In German)

51. Umeki S, Tamai H, Yagi S, Soejima R, Higashi Y: Harlequin syndrome due to a spinal invasion of the left apical lung cancer. Rinsho Shinkeigaku 30: 94-99, 1990 (In Japanese)

52. Warlow CP, Dennis MS, van Gijn J, Hankey GJ, Sandercock PAG, Bamford JM, Wardlaw JM: What caused this subarachnoid hemorrhage? In: Stroke: A Practical Guide to Management. Oxford: Blackwell Science, 2001:376-413

53. Warwicl V: The ocular parasympathetic nerve supply and its mesencephalic sources. J Anat 88:71-93, 1954

54. Wright L: Cell survival in chick embryo ciliary ganglion is reduced by chronic ganglionic blockade. Brain Res 227: 283286, 1981

55. Zhang, YL, Tan CK, Wong WC: An ultrastructural study of the ciliary ganglia of the cat and monkey (Macaca fascicularis) following preganglionic axotomy. Neurodegeneration 5: 367377,1996

56. Zhang YL, Tan CK, Wong WC: The ciliary ganglion of the monkey: A light and electron microscope study. J Anat 184: $251-260,1994$ 